\title{
Heightened Attentional Capture by Visual Food Stimuli in Anorexia Nervosa
}

Citation for published version (APA):

Neimeijer, R. A. M., Roefs, A., \& de Jong, P. J. (2017). Heightened Attentional Capture by Visual Food Stimuli in Anorexia Nervosa. Journal of Abnormal Psychology, 126(6), 805-811.

https://doi.org/10.1037/abn0000275

Document status and date:

Published: 01/08/2017

DOI:

10.1037/abn0000275

Document Version:

Publisher's PDF, also known as Version of record

Document license:

Taverne

Please check the document version of this publication:

- A submitted manuscript is the version of the article upon submission and before peer-review. There can be important differences between the submitted version and the official published version of record.

People interested in the research are advised to contact the author for the final version of the publication, or visit the DOI to the publisher's website.

- The final author version and the galley proof are versions of the publication after peer review.

- The final published version features the final layout of the paper including the volume, issue and page numbers.

Link to publication

\footnotetext{
General rights rights.

- You may freely distribute the URL identifying the publication in the public portal. please follow below link for the End User Agreement:

www.umlib.nl/taverne-license

Take down policy

If you believe that this document breaches copyright please contact us at:

repository@maastrichtuniversity.nl

providing details and we will investigate your claim.
}

Copyright and moral rights for the publications made accessible in the public portal are retained by the authors and/or other copyright owners and it is a condition of accessing publications that users recognise and abide by the legal requirements associated with these

- Users may download and print one copy of any publication from the public portal for the purpose of private study or research.

- You may not further distribute the material or use it for any profit-making activity or commercial gain

If the publication is distributed under the terms of Article $25 \mathrm{fa}$ of the Dutch Copyright Act, indicated by the "Taverne" license above, 


\title{
Heightened Attentional Capture by Visual Food Stimuli in Anorexia Nervosa
}

\author{
Renate A. M. Neimeijer \\ University of Groningen and Accare Child and Adolescent \\ Psychiatry, Smilde, the Netherlands
}

\author{
Anne Roefs \\ Maastricht University
}

Peter J. de Jong

University of Groningen

\begin{abstract}
The present study was designed to test the hypothesis that anorexia nervosa (AN) patients are relatively insensitive to the attentional capture of visual food stimuli. Attentional avoidance of food might help AN patients to prevent more elaborate processing of food stimuli and the subsequent generation of craving, which might enable AN patients to maintain their strict diet. Participants were 66 restrictive AN spectrum patients and 55 healthy controls. A single-target rapid serial visual presentation task was used with food and disorder-neutral cues as critical distracter stimuli and disorder-neutral pictures as target stimuli. AN spectrum patients showed diminished task performance when visual food cues were presented in close temporal proximity of the to-be-identified target. In contrast to our hypothesis, results indicate that food cues automatically capture AN spectrum patients' attention. One explanation could be that the enhanced attentional capture of food cues in AN is driven by the relatively high threat value of food items in AN. Implications and suggestions for future research are discussed.
\end{abstract}

\section{General Scientific Summary}

The current study tested the hypothesis that people with anorexia nervosa show attentional avoidance of food. This might help them to persist in their restrictive food intake. In contrast with the hypothesis, it was shown that anorexia patients were highly distracted by food pictures compared to healthy controls.

Keywords: rapid serial visual presentation task, temporal attentional bias, anorexia nervosa

Anorexia nervosa (AN) is a mental disorder characterized by a fear of gaining weight despite existing underweight. According to the cognitive-behavioral theory of eating disorders, the overevaluation of control over eating, shape, and weight is of primary importance in maintaining the disorder (Fairburn, Cooper, Shafran, \& Wilson, 2008). In line with this, it has been argued that people with AN are characterized by dysfunctional self-schemata related to body size that are reinforced by functionally related informationprocessing biases such as attentional bias (Williamson, White, YorkCrowe, \& Stewart, 2004). For instance, when walking past a mirror,

This article was published Online First April 27, 2017.

Renate A. M. Neimeijer, Department of Clinical Psychology and Experimental Psychopathology, University of Groningen, and Department of Eating Disorders, Accare Child and Adolescent Psychiatry, Smilde, the Netherlands; Anne Roefs, Department of Clinical Psychological Science, Faculty of Psychology \& Neuroscience, Maastricht University; Peter J. de Jong, Department of Clinical Psychology and Experimental Psychopathology, University of Groningen.

Correspondence concerning this article should be addressed to Renate A. M. Neimeijer, Department of Clinical Psychology and Experimental Psychopathology, University of Groningen, Grote Kruisstraat 2/1, 9712 TS Groningen, the Netherlands. E-mail: r.a.m.neimeijer@rug.nl the attention of a person with AN might be automatically captured by disliked body parts (Glashouwer, Jonker, Thomassen, \& de Jong, 2016).

Also, attention to food stimuli might be biased. Experimental studies have found that when hungry, people typically show a heightened attentional bias toward food cues as indexed by both color-naming interference effects in a modified Stroop task using food versus nonfood words (Lavy \& van den Hout, 1993) and automatic spatial orientation toward food stimuli in a visual probe task (Nijs, Muris, Euser, \& Franken, 2010). Such heightened attention for food cues has been argued to enhance craving, which in turn may promote further the attentional bias for food cues. Thus, people may enter an attentional bias-craving cycle that eventually lowers the threshold for actual food intake (cf. Franken, 2003).

It might, however, be that after prolonged and repeated starvation, food loses its motivational salience (e.g., Veenstra \& de Jong, 2011) and thereby also its attention-grabbing power. If so, this may help prevent AN patients to enter this attentional bias-craving cycle and thus help them in persisting their restrictive food intake. In line with this, previous research using a free viewing task involving food stimuli found evidence for attentional avoidance of food in AN patients (Giel et al., 2011). In this task, picture pairs 
(food/disorder neutral) appeared on the computer screen. By means of eye-tracking methodology, it was shown that AN patients spent less time looking at food pictures than comparison participants without an eating disorder. Conceptually similar results (avoidance of high-caloric food) were found in a study using a pictorial exogenous cueing task in AN patients (Veenstra \& de Jong, 2012). The exogenous cueing task (ECT) is a reaction time (RT)-based spatial attention task in which participants are asked to detect a visual target presented at a left or right peripheral location. In this study, the target was preceded by a task-irrelevant picture (food or disorder neutral) that in half of the trials validly cued the target's spatial location, whereas in the other half of the trials, the preceding stimulus was presented at the opposite spatial location of the target and thus invalidly cued the target's location. In line with previous research using the ECT, participants were generally faster on validly than invalidly cued trials. Yet, specifically when targets were preceded by pictures displaying highcaloric food items, there was no difference in participants' response time between validly and invalidly cued trials. The finding that participants were not relatively fast on valid trials when preceded by pictures of high-caloric food can be interpreted as a tendency to direct attention away from these food stimuli.

There is, however, also evidence that points in the opposite direction. A study using a visual dot probe task with women with various types of eating disorders found that patients exhibited attentional avoidance of pictures of low-caloric eating situations but an approach bias with regard to pictures displaying highcaloric food situations (Shafran, Lee, Cooper, Palmer, \& Fairburn, 2007). Also, such a visual probe task is a RT-based measure in which participants have to respond to a target (the probe), which is preceded by a task-irrelevant stimulus. A critical difference with the ECT is that in the visual probe task pairs of task-irrelevant stimuli are presented. In this particular study, these pairs always consisted of a nonfood and a food picture, and probes were equally often presented at the location of the preceding food as of the preceding nonfood stimulus. The tendency to direct attention away from food and/or toward nonfood stimuli (attentional avoidance) would result in relatively slow responses on trials for which the probe was presented at the same location as the preceding food stimulus as compared to trials for which the probe was presented at the opposite location of the preceding food stimulus (i.e., at the location of the nonfood stimulus). Finally, a previous study using a pictorial visual search task found increased instead of reduced distraction by high-caloric food cues in eating disorder patients compared to healthy controls (Smeets, Roefs, van Furth, \& Jansen, 2008). In this task, participants were instructed to detect a neutral target word among either disorder-relevant or neutral distractor words. Slower RTs on trials with disorder-relevant distractors than on trials with neutral distractors indicated increased distraction by disorder-relevant words in eating disorder patients. No evidence was found for speeded detection of high-caloric food words within an array of neutral distractor pictures. Thus, overall, the existing literature does not provide a straightforward outcome.

There are several explanations for these mixed results. First, these studies used different paradigms (dot probe, ECT, visual search task, and free viewing task), and some studies (Shafran et al., 2007; Smeets et al., 2008) included not only AN patients but also patients with bulimia nervosa $(\mathrm{BN})$, binge eating disorder (BED), or eating disorder not otherwise specified. The eating pattern of both $\mathrm{BN}$ and BED patients is characterized by periods of loss of control over eating. These patients might therefore show different biases than women with $\mathrm{AN}$, and this might have contributed to the finding that specifically the studies with mixed patient groups found evidence for an attentional bias toward food and distraction by food stimuli, whereas the studies with exclusively AN patients found attentional avoidance of food cues.

Second, all paradigms that were used in these earlier studies focused on the spatial dimension of attentional bias: the tendency to direct the visual attention toward (or away from) specific cues. Attention is, however, distributed not only over space but also over time. The visual world is bursting with information, and stimuli continually compete for a perceiver's attention: Stimuli that win often reach awareness, whereas those that lose frequently go unnoticed (Most, Smith, Cooter, Levy, \& Zald, 2007). Little is known about the consequences of continued attention for foodrelated information for the processing of other (concurrently or subsequently appearing) information. Once a food stimulus has captured attention, it may be preferentially processed and granted prioritized access to limited cognitive resources (cf. Koster, de Raedt, Verschuere, Tibboel, \& de Jong, 2009). Such privileged access may not only prevent new information from entering working memory but also provide the opportunity for more elaborate processing of the food stimulus, which in turn may promote craving and actual approach behavior.

A task often used to measure the temporal dynamics of attention is the Rapid Serial Visual Presentation (RSVP) task (Raymond, Shapiro, \& Arnell, 1992). In the single-target version of this task, a target that is preceded by a distractor has to be identified in a stream of stimuli (e.g., landscapes) that is presented in the center of participants' attention (e.g., Most, Chun, Widders, \& Zald, 2005). These stimuli are presented in quick succession (e.g., 118 $\mathrm{ms} / \mathrm{stimulus}$ ) without interstimulus interval. The time window between the distractor and the target can be manipulated by adding more or fewer filler stimuli between the distractor and the target. A salient distractor can prevent the target identification if it is presented shortly before the target, even when the distractor is task irrelevant and can be best ignored for optimal task performance. Missing the target is usually most likely to occur in the shorter time lags.

Previous RSVP studies in the context of eating disorder symptoms showed that motivational salience is an important factor in (temporal) attentional bias. Accordingly, a study comparing hungry and satiated participants showed that specifically in hungry participants, task performance was hampered when a food distractor was presented in close temporal proximity to the target (Piech, Pastorino, \& Zald, 2010). Most important for the current context, it was found that this food-based temporal attentional bias is also associated with individual differences in eating behavior tendencies. More specifically, it was found that food distractors resulted in stronger temporal attentional bias (as indexed by hampered target identification) for restrained than for unrestrained eaters (Neimeijer, de Jong, \& Roefs, 2013). Such nonintentional (bottomup) tendency to prioritize the processing of food cues may help explain why restrained eaters fail so often despite their strong intention to lose weight. In line with this, it was found that specifically for binge eaters, food stimuli were relatively often accurately identified when presented in the "attentional blink," the period where information is usually missed, suggesting that food 
stimuli received processing priority (Schmitz, Naumann, Biehl, \& Svaldi, 2015). This might enhance the chance that food elicits craving with a binge as a result.

Together, the available evidence in the context of studies that used the RSVP suggests that people who often fail in regulating their food intake (e.g., restrained eaters, patients with BED) show a preferential processing of food stimuli that interferes with their current goals. Perhaps, then, in contrast with hungry people, restrained eaters, and patients with BED, AN patients might be very efficient in preventing more elaborate processing of food stimuli and subsequent craving. If so, this would help $\mathrm{AN}$ patients to persist in their diet goal. Therefore, the present study was designed to test the hypothesis that AN patients are relatively insensitive to the attentional capture of food stimuli and therefore show diminished attentional distraction by visual food cues within the context of a single-target RSVP.

\section{Method}

\section{Participants}

Participants were treatment-seeking female adolescents who were admitted to the Center for Eating Disorders of Accare Child and Adolescent Psychiatry (Smilde, the Netherlands). For this study, we selected a group of restricting eaters by including a group of broadly defined AN patients $(n=66)$, using the Eating Disorder Examination (EDE; Bryant-Waugh, Cooper, Taylor, \& Lask, 1996; Dutch version: Decaluwé \& Braet, 1999). Next to patients who met all of the DSM-IV (American Psychiatric Association, 1994) criteria of the restrictive type of AN $(n=33)$, we included patients who met most but not all criteria, that is, patients with menses $(n=5)$, with only light underweight $(1-15 \%, n=$ $16)$, patients who were nonfat phobic $\mathrm{AN}(n=2)$, and other partial AN (meeting two of four criteria, $n=10$; cf. Thomas, Vartanian, \& Brownell, 2009). Age ranged from 12-23 years. For the comparison control group, we selected symptom-free female adolescents $(n=55)$ within the same age range from secondary schools in Groningen. Educational level was determined as high or low within the Dutch system. The percentage of highly educated participants in the patient and control groups was 58 and 69, respectively, and this did not differ between groups, $\chi^{2}(1, N=119)=$ $0.09, p=.77$.

\section{Materials}

RSVP. The RSVP was programmed in E-prime 2.0 (Schneider, Eschman, \& Zuccolotto, 2002) administered on a laptop. A single-target version of the task was designed with foodrelated and disorder-neutral (control) distractors (Neimeijer et al., 2013). Every trial consisted of a stream of pictures that were presented for $118 \mathrm{~ms}$ without interstimulus interval. Each stream contained one distractor and one neutral target stimulus. Target pictures had a 10-pixel blue frame, while all other stimuli had a 10-pixel black frame. The number of pictures within a particular stream (10-19 pictures) depended on the position of the distractor and the number of stimuli between distractor and target ( 1 or 7$)$ stimulus. The target was always followed by a fixed number of four fillers, to ensure that any differences in results across types of trials could not be attributed to a variable time the final target had to be kept in working memory. The order of the trials, as well as which pictures were paired with which lag, was individually randomized. The distractor was randomly presented on one of three possible positions in the stream $(4,6,8)$. The target was randomly presented at Lag 2 or 8 following the distractor. In the present setup, there were 2 (type of distractor: food, neutral) $\times 3$ (distractor position: $4,6,8) \times 2$ (lag: 2,8$)=12$ different types of trials, each presented six times. See Figure 1 for a visual overview of the task.

Stimuli measuring $550 \times 550$ pixels were photographs: 46 high-caloric food stimuli, 57 disorder-neutral pictures, and 75 fillers (landscapes). Food pictures were derived from Istockphoto, whereas disorder-neutral photos were derived from the International Affective Picture System. Both types of pictures were previously used in Neimeijer et al. (2013). Disorderneutral pictures were chosen so that there was great variety and consisted of people, animals, and everyday objects like money, a book, and shoes. Food pictures consisted of a wide range of high-caloric palatable food pictures, like fries, a burger, cake, chocolate, and a pizza.

The RSVP started with a four-trial practice session. Hereafter, a total number of trials were presented in three similar blocks of 24 trials, with a 30 -s break between the blocks to reduce the influence of fatigue and problems with participants' concentration. After each trial, participants were asked to type what they had seen on the picture with the blue frame (targets)

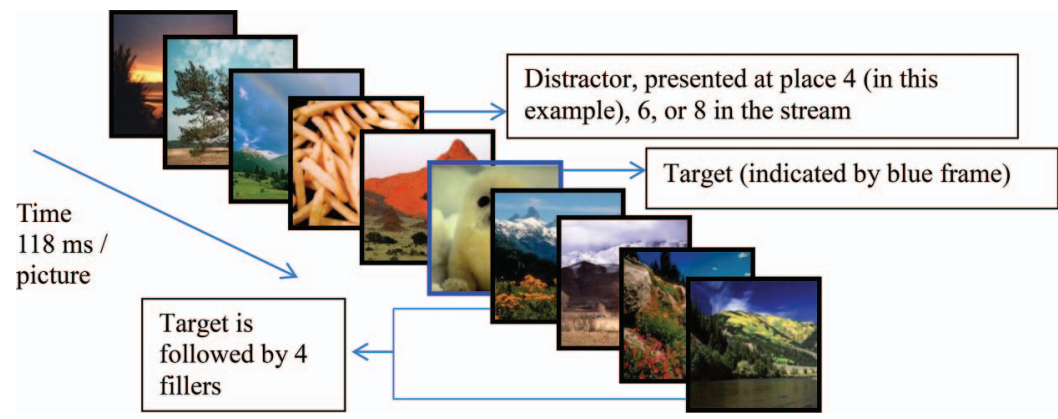

Figure 1. Example of a single-target trial, Lag 2. See the online article for the color version of this figure. 


\section{Questionnaires}

Eating Disorder Examination Questionnaire. The child version of the Eating Disorder Examination-Questionnaire (EDE-Q; Fairburn \& Bèglin, 1994; Decaluwé, 1999) was administered to allow for a comparison of eating disorder pathology between AN-like patients and healthy controls. The EDE-Q is the questionnaire version of the Eating Disorder Examination interview and consists of four subscales ( $0-6$ points): restraint, eating concern, weight concern, and shape concern. The total EDE-Q score provides a global measure of the severity of eating disorder pathology.

Visual Analog Scales. Participants' craving, liking, and frequency with which they ate the food items represented on the pictures that were used in the RSVP procedure were assessed on a Visual Analog Scale (VAS) ranging from 0 (not at all) to 100 (very much/very often). To index craving, we asked, "How much do you crave this product at this moment?" Liking of food items of the tasks was assessed by answering the following question: "How much do you like this product?" To assess the frequency with which they ate the particular food, we asked, "How frequently do you eat this product?"

Hunger Scale. The Hunger Scale (Grand, 1968) consists of four items (time since last eating, subjective hunger, estimate of the amount of favorite food able to eat, estimate of time until next expected meal) and was administered to control for possible differences in hunger across groups. Since time since last eating is the considered the most objective measure of hunger, this variable was used to control for the influence of hunger.

\section{Procedure}

The study was approved by the Medical Ethical Committee of the University Medical Center Groningen, protocol number 2011.193. Before participants were scheduled for the assessment, both patients and their parents gave informed consent. After the RSVP, the VAS, and Hunger Scale were filled out. Finally, height and weight were measured.

\section{Data Reduction}

After the total experiment was finished, the experimenter checked whether the answers of the participants where correct (excluding typos) and specific. In order to derive a measure for temporal attentional bias, percent correct identified targets as a function of distractor (food, neutral) and lag $(2,8)$ was calculated. Percentage underweight was derived from the 50th percentile of height and age.

\section{Results}

\section{Group Characteristics}

See Table 1 for a description of the participants and statistics of the between-groups tests. In line with the inclusion criteria, AN spectrum patients had a higher percentage of underweight and higher EDE-Q scores. AN spectrum patients showed less craving, liking, and frequency of eating the foods than healthy controls. Furthermore, AN spectrum patients reported longer time since last eating and a trend toward a significantly longer time until expected next meal but less subjective hunger and lower amount of favorite food that could be eaten right now. Eating-disordered patients and healthy controls did not differ with respect to their age.

\section{Temporal Attentional Bias}

Mean percentages of correctly identified neutral targets after either a food or a neutral distractor are presented in Table 2. A 2 (lag: 2,8$) \times 2$ (distractor type: neutral, food) $\times 2$ (group: $\mathrm{AN}$, control) mixed analysis of variance showed a main effect of lag, $F(1,119)=124.31, p<.01, \eta_{\mathrm{p}}^{2}=.51$. Participants were overall more accurate in identifying targets when presented at Lag 8 than at Lag 2 following the distractor stimulus. Thus, presenting a task-irrelevant distractor elicited an "attentional blink." Furthermore, there was a main effect of group, $F(1,119)=6.03, p=.02$, $\eta_{\mathrm{p}}^{2}=.05$, indicating that AN spectrum patients generally showed a lower rate of accurate target identification. There was no main effect of distractor type, $F(1,119)=0.99, p=.32, \eta_{\mathrm{p}}^{2}=<0.01$, indicating that in general, participants did not have more difficulties identifying a target after a food than after a neutral distractor stimulus. Most relevant for the present context, there was a Distracter type $\times$ Group effect, $F(1,119)=8.63, p<.01, \eta_{p}^{2}=.07$, indicating that there was a difference between the two groups as a function of type of distracter. Independent sample $t$ tests showed that there was no difference between the two groups in percentage

Table 1

Group Characteristics

\begin{tabular}{|c|c|c|c|c|c|c|}
\hline \multirow[b]{2}{*}{ Characteristic } & \multicolumn{2}{|c|}{ AN } & \multicolumn{2}{|c|}{ Control } & \multicolumn{2}{|c|}{$\begin{array}{c}\text { Between-groups } \\
\text { test }\end{array}$} \\
\hline & $M$ & $S D$ & $M$ & $S D$ & $t$ & $p$ \\
\hline Age & 15.25 & 1.86 & 15.45 & 1.79 & 1.03 & .31 \\
\hline Underweight $\%$ & 17.32 & 9.3 & -3.98 & 10.41 & 11.83 & $<.001$ \\
\hline Body mass index & 16.14 & 1.9 & 20.45 & 2.10 & 11.62 & $<.001$ \\
\hline EDE-Q total score & 4.09 & 1.26 & 1.24 & 1.03 & 13.15 & $<.001$ \\
\hline HS: time since last meal (hr) & 8.05 & 8.50 & 1.70 & 1.67 & 4.97 & $<.001$ \\
\hline HS: subjective hunger (1-6) & 2.21 & 1.52 & 3.27 & 1.89 & 4.33 & $<.001$ \\
\hline HS: amount of favorite food able to eat $(1-7)$ & 2.19 & 1.73 & 3.35 & 1.77 & 4.42 & $<.001$ \\
\hline HS: time until next meal & 6.47 & 7.03 & 4.92 & 4.52 & 1.66 & .09 \\
\hline
\end{tabular}

Note. Percentage underweight was derived from the 50th percentile of height and age. AN $=$ anorexia nervosa; EDE-Q = Eating Disorder Examination-Questionnaire; HS = Hunger Scale. 
Table 2

Percentage Correctly Identified Targets as a Function of Type of Distractor and Lag

\begin{tabular}{lcclll}
\hline & \multicolumn{2}{c}{ AN } & & \multicolumn{2}{c}{ Control } \\
\cline { 2 - 3 } \cline { 6 - 6 } Group & D: Food & D: Neutral & & D: Food & D: Neutral \\
\hline Lag 2 & $56.6(23.6)$ & $67.5(17.9)$ & & $73.8(20.4)$ & $73.4(18)$ \\
Lag 8 & $81.2(16.2)$ & $80.6(15.8)$ & & $85.44(13.1)$ & $82.2(14.1)$ \\
\hline
\end{tabular}

Note. $\mathrm{AN}=$ anorexia nervosa; $\mathrm{D}=$ distractor.

correctly identified pictures after a neutral distracter, $t(119)=$ $1.43, p=.16, d=.26$, but there was a difference in performance on trials with a food distracter, $t(119)=3.10, p<.01, d=.57$. AN spectrum patients were more distracted by food cues, thereby hampering subsequent target detection. Although the effect seemed most pronounced for Lag 2, the Distracter $\times$ Group $\times$ Lag interaction was not significant, $F(1,119)=2.05, p=.16, \eta_{\mathrm{p}}^{2}=$ .02 . The effect remained stable if controlled for hunger (using time since last eating as a covariate), $F(1,119)=8.40, p<.01, \eta_{\mathrm{p}}^{2}=$ .05 , so the effects cannot be attributed to more hunger in the patient group. See Figure 2 for a visual presentation of the results. In order to further explore the relationship between eating disorder symptoms and RSVP performance, difference scores were calculated (percent correct identified food pictures minus percent correct identified neutral pictures) for both lags, thereby controlling for general RSVP performance. Negative scores indicate an attentional bias for food stimuli. This RSVP difference score for Lag 2 was significantly associated with all EDE-Q subscales: restraint, $r(121)=-.21, p=.02$; eating concerns, $r(121)=-.23, p=.01$; weight concerns, $r(121)=-.19, p=.04$; and shape concerns, $r(121)=-.23, p=.01$, indicating that more severe eating disorder symptoms were associated with a stronger attentional bias. There were no significant correlations between EDE-Q scores and the difference scores for Lag 8 , all $r \mathrm{~s}(128)<-.05$, all $p \mathrm{~s}>$ .60 .

\section{Discussion}

The present study was a first attempt to investigate temporal attentional bias for food in AN spectrum patients. The results clearly indicate that in AN spectrum patients, target detection is hampered when it is preceded by a food distractor and that more severe eating disorder pathology is associated with a stronger attentional bias for food cues. Thus, in contrast with the hypothesis, AN spectrum patients showed a bottom-up attentional capture by visual food cues that interfered with their current task (i.e., target identification). This is in line with some earlier studies on (spatial) attentional bias that also showed heightened distraction by food stimuli in eating disorder patients (Shafran et al., 2007; Smeets et al., 2008).

The hypothesis that food has lost its attention-grabbing power in AN spectrum patients (e.g., through prolonged starvation and repeated exposure to food without consequently eating) is not supported by these findings. In fact, prolonged food deprivation might have led to an even stronger attentional bias for food. The addiction account of attention states that there is a reciprocal relationship between attention for food and craving (Nijs et al., 2010). The current finding that AN spectrum patients show atten- tional capture by food stimuli might then reflect heightened craving in these patients. Also, earlier studies link temporal attentional bias and craving (Neimeijer et al., 2013; Piech et al., 2010; Schmitz et al., 2015). AN patients show an attentional bias but do not get caught in the attentional bias-craving-eating cycle. This seems to imply that they have high self-regulation skills to resist food-related short-term reinforcement that runs counter to their diet goal. In other words, it seems that (attentional) avoidance of food cues in AN is not so much sustained by attenuated automatic attentional capture but reflects processes involving more top-down control.

The heightened attentional capture might also be driven by the threat value of food. That is, food cues might not only be salient because of their hedonic value but, especially in $\mathrm{AN}$, also because of their threatening associations with gaining weight and losing control over eating. Indeed, previous research consistently found that negative stimuli (e.g., trauma reminders) can capture and hold attention, as well as hamper ongoing task performance (e.g., Most et al., 2005; Olatunji, Armstrong, McHugo, \& Zald, 2013; Verwoerd, Wessel, \& de Jong, 2010). When a fear-associated stimulus is detected, processing resources are automatically diverted from less salient cues to these feared stimuli in order to escape the danger as quickly as possible. Hyperattention to feared stimuli can, therefore, facilitate an early escape (cf. Lavy, van den Hout, \& Arntz, 1993). Although there was no significant effect for lag in the current study, the effect seemed most prominent when the distractor was presented in close temporal proximity of the target (Lag 2). The correlational analysis also showed that stronger attentional bias in Lag 2 was associated with more severe eating disorder pathology. This might indicate that there is an initial vigilance for food cues and that attention bias is "recovered" on the longer lag (see also Most et al., 2005). It could also be that even a subsequent avoidance is shown, a pattern that is also seen in the context of anxious concerns (e.g., Mogg, Bradley, Miles, \& Dixon, 2004).

An attentional bias for food in AN might thus reflect fear of gaining weight or losing control over eating and could contribute to dietary restraint and (behavioral) avoidance of food stimuli. It might, however, also be that the threat for AN patients is approaching the food and giving in to the craving they may experience. As

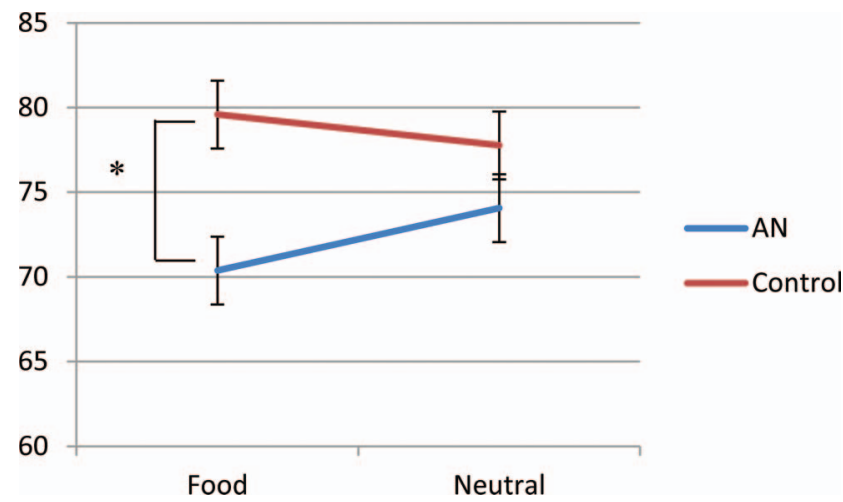

Figure 2. Percentage correctly identified targets as a function of distracter type. $\mathrm{AN}=$ anorexia nervosa. ${ }^{*} p<.01$. See the online article for the color version of this figure. 
earlier described, especially for underweight participants, the prolonged food deprivation and the basic organismic need for nutrition might have led to an attentional bias for food, which in turn may lower the threshold for nonintended food consumption. In the meantime, a quick detection of food cues may also help to quickly escape from stimuli or contexts that signal food intake, thereby supporting their ongoing diet goal.

The current pattern of findings cannot be attributed to a generally worse performance of AN spectrum patients on the RSVP task because the difference between patients and the control group was restricted to food distracters. Also, the presence of hunger does not explain the differences, as the main results remained unaffected when we statistically controlled for hunger. However, it should be mentioned that ongoing food deprivation may not be fully captured by time since last meal or subjective hunger.

AN spectrum patients did also more generally show lower identification rates than healthy controls, which may be caused by underweight, as underweight is known to influence cognitive processes such as thinking and concentration (Keys, Brožek, Henschel, Mickelsen, \& Taylor, 1950). Because restrictive food intake is in particular a feature of the restricting anorexia, we only included this subtype. Therefore, the results cannot be generalized to all anorexia patients (i.e., the binge/purging subtype). It seems plausible that binge/purging individuals may show the same pattern of finding, but future research is necessary to test this.

To conclude, in this study, temporal attentional bias in a large group of AN spectrum patients was tested. Patients showed heightened distraction by food cues, which might indicate that food cues are highly salient. It remains unclear whether this means that AN spectrum patients do experience automatic craving for food (as an analogue with addiction) or that food has a high threat value (as an analogue with anxiety) or both (when the threat is approaching the food and give in to craving). In addition, an important next question is whether biased attention for food is an epiphenomenon when having eating concerns or has also a causal relationship with these concerns. A first step to examine whether it contributes to the maintenance of the disorder would be to test if the temporal attentional bias would normalize under influence of (successful) treatment and if a (more pronounced) bias predicts worse treatment outcome.

\section{References}

American Psychiatric Association. (1994). Diagnostic criteria from DSMIV. Washington, DC: Author.

Bryant-Waugh, R. J., Cooper, P. J., Taylor, C. L., \& Lask, B. D. (1996). The use of the eating disorder examination with children: A pilot study. International Journal of Eating Disorders, 19, 391-397. http://dx.doi .org/10.1002/(SICI) 1098-108X(199605)19:4<391::AID-EAT6>3.0 .CO;2-G

Decaluwé, V., \& Braet, C. (1999). Dutch translation of the Child Eating Disorder Examination, authored by C. G. Fairburn, Z. Cooper, \& R. Bryant-Waugh. Unpublished manuscript.

Fairburn, C. G., \& Bèglin, S. J. (1994). Assessment of eating disorders: Interview or self-report questionnaire? International Journal of Eating Disorders, 16, 363-370.

Fairburn, C. G., Cooper, Z., Shafran, R., \& Wilson, G. T. (2008). Eating disorders: A transdiagnostic protocol. In D. H. Barlow (Ed.), Clinical handbook of psychological disorders: A step-by-step treatment manual (4th ed., pp. 578-614). New York, NY: Guilford. http://dx.doi.org/10
.1002/1098-108X(199412)16:4<363::AID-EAT2260160405>3.0.CO; 2-\#

Franken, I. H. A. (2003). Drug craving and addiction: Integrating psychological and neuropsychopharmacological approaches. Progress in Neuro-Psychopharmacology \& Biological Psychiatry, 27, 563-579. http://dx.doi.org/10.1016/S0278-5846(03)00081-2

Giel, K. E., Friederich, H. C., Teufel, M., Hautzinger, M., Enck, P., \& Zipfel, S. (2011). Attentional processing of food pictures in individuals with anorexia nervosa-An eye-tracking study. Biological Psychiatry, 69, 661-667. http://dx.doi.org/10.1016/j.biopsych.2010.09.047

Glashouwer, K. A., Jonker, N. C., Thomassen, K., \& de Jong, P. J. (2016). Take a look at the bright side: Effects of positive body exposure on selective visual attention in women with high body dissatisfaction. Behaviour Research and Therapy, 83, 19-25. http://dx.doi.org/10.1016/ j.brat.2016.05.006

Grand, S. (1968). Color-word interference: II. An investigation of the role of vocal conflict and hunger in associative priming. Journal of Experimental Psychology, 77, 31-40. http://dx.doi.org/10.1037/h0025759

Keys, A., Brožek, J., Henschel, A., Mickelsen, O., \& Taylor, H. L. (1950). The biology of human starvation (Vols. 1-2). Minneapolis, MN: University of Minnesota Press.

Koster, E. H. W., de Raedt, R., Verschuere, B., Tibboel, H., \& de Jong, P. J. (2009). Negative information enhances the attentional blink in dysphoria. Depression and Anxiety, 26, E16-E22. http://dx.doi.org/10 $.1002 /$ da. 20420

Lavy, E. H., \& van den Hout, M. A. (1993). Attentional bias for appetitive cues: Effects of fasting in normal subjects. Behavioural and Cognitive Psychotherapy, 21, 297-310. http://dx.doi.org/10.1017/S13524658000 11632

Lavy, E. H., van den Hout, M., \& Arntz, A. (1993). Attentional bias and spider phobia: Conceptual and clinical issues. Behaviour Research and Therapy, 31, 17-24. http://dx.doi.org/10.1016/0005-7967(93)90038-V

Mogg, K., Bradley, B., Miles, F., \& Dixon, R. (2004). Brief report time course of attentional bias for threat scenes: Testing the vigilanceavoidance hypothesis. Cognition and Emotion, 18, 689-700. http://dx .doi.org/10.1080/02699930341000158

Most, S. B., Chun, M. M., Widders, D. M., \& Zald, D. H. (2005). Attentional rubbernecking: Cognitive control and personality in emotion-induced blindness. Psychonomic Bulletin \& Review, 12, 654661. http://dx.doi.org/10.3758/BF03196754

Most, S. B., Smith, S. D., Cooter, A. B., Levy, B. N., \& Zald, D. H. (2007). The naked truth: Positive, arousing distractors impair rapid target perception. Cognition and Emotion, 21, 964-981. http://dx.doi.org/10 $.1080 / 02699930600959340$

Neimeijer, R. A. M., de Jong, P. J., \& Roefs, A. (2013). Temporal attention for visual food stimuli in restrained eaters. Appetite, 64, 5-11. http://dx .doi.org/10.1016/j.appet.2012.12.013

Nijs, I. M., Muris, P., Euser, A. S., \& Franken, I. H. (2010). Differences in attention to food and food intake between overweight/obese and normalweight females under conditions of hunger and satiety. Appetite, 54, 243-254. http://dx.doi.org/10.1016/j.appet.2009.11.004

Olatunji, B. O., Armstrong, T., McHugo, M., \& Zald, D. H. (2013). Heightened attentional capture by threat in veterans with PTSD. Journal of Abnormal Psychology, 122, 397-405. http://dx.doi.org/10.1037/ a0030440

Piech, R. M., Pastorino, M. T., \& Zald, D. H. (2010). All I saw was the cake: Hunger effects on attentional capture by visual food cues. Appetite, 54, 579-582. http://dx.doi.org/10.1016/j.appet.2009.11.003

Raymond, J. E., Shapiro, K. L., \& Arnell, K. M. (1992). Temporary suppression of visual processing in an RSVP task: An attentional blink? Journal of Experimental Psychology: Human Perception and Performance, 18, 849-860. http://dx.doi.org/10.1037/0096-1523.18.3.849

Santel, S., Baving, L., Krauel, K., Münte, T. F., \& Rotte, M. (2006). Hunger and satiety in anorexia nervosa: FMRI during cognitive process- 
ing of food pictures. Brain Research, 1114, 138-148. http://dx.doi.org/ 10.1016/j.brainres.2006.07.045

Schmitz, F., Naumann, E., Biehl, S., \& Svaldi, J. (2015). Gating of attention towards food stimuli in binge eating disorder. Appetite, 95, 368-374. http://dx.doi.org/10.1016/j.appet.2015.07.023

Schneider, W., Eschman, A., \& Zuccolotto, A. (2002). E-prime reference guide. Pittsburgh, PA: Psychology Software Tools.

Shafran, R., Lee, M., Cooper, Z., Palmer, R. L., \& Fairburn, C. G. (2007). Attentional bias in eating disorders. International Journal of Eating Disorders, 40, 369-380. http://dx.doi.org/10.1002/eat.20375

Smeets, E., Roefs, A., van Furth, E., \& Jansen, A. (2008). Attentional bias for body and food in eating disorders: Increased distraction, speeded detection, or both? Behaviour Research and Therapy, 46, 229-238. http://dx.doi.org/10.1016/j.brat.2007.12.003

Thomas, J. J., Vartanian, L. R., \& Brownell, K. D. (2009). The relationship between eating disorder not otherwise specified (EDNOS) and officially recognized eating disorders: Meta-analysis and implications for DSM. Psychological Bulletin, 135, 407-433. http://dx.doi.org/10.1037/ a0015326

Veenstra, E. M., \& de Jong, P. J. (2011). Reduced automatic motivational orientation towards food in restricting anorexia nervosa. Journal of
Abnormal Psychology, 120, 708-718. http://dx.doi.org/10.1037/ a0023926

Veenstra, E. M., \& de Jong, P. J. (2012). Attentional bias in restrictive eating disorders. Stronger attentional avoidance of high-fat food compared to healthy controls? Appetite, 58, 133-140. http://dx.doi.org/10 1016/j.appet.2011.09.014

Verwoerd, J., Wessel, I., \& de Jong, P. J. (2010). Attentional bias for trauma-film reminders: Towards a laboratory analogue for studying the role of attention in the persistence of intrusive memories. Applied Cognitive Psychology, 24, 425-436. http://dx.doi.org/10.1002/acp.1687

Williamson, D. A., White, M. A., York-Crowe, E., \& Stewart, T. M. (2004). Cognitive-behavioral theories of eating disorders. Behavior Modification, 28, 711-738. http://dx.doi.org/10.1177/014544550325 9853

Received September 14, 2016

Revision received March 24, 2017

Accepted March 26, 2017

\section{E-Mail Notification of Your Latest Issue Online!}

Would you like to know when the next issue of your favorite APA journal will be available online? This service is now available to you. Sign up at https://my.apa.org/portal/alerts/ and you will be notified by e-mail when issues of interest to you become available! 